\title{
Perfil do Executivo no Mercado Globalizado
}

\author{
Simone Echeveste \\ Berenice Vieira \\ Débora Viana \\ Guilherme Trez \\ Carlos Panosso
}

\section{RESUMO}

Impulsionadas pela globalização, empresas transnacionais, instaladas no Brasil, estão colaborando para a formação de um novo perfil profissional para executivos brasileiros. As mudanças que derivam deste cenário passam a exigir dos profissionais conhecimentos e aptidões diferenciadas para a atuação no ambiente atual de negócios. O presente estudo busca traçar o perfil ideal do executivo em face das exigências do mercado globalizado, destacando-se os principais atributos que este profissional deve apresentar, segundo a visão de profissionais decisores das 500 maiores empresas do ranking da revista Exame (1997). Realizou-se uma pesquisa descritiva, a partir de duas etapas: uma exploratória, na qual se geraram os atributos a serem avaliados e uma quantitativa, para a mensuração do grau de importância de cada indicador arrolado. Os atributos referentes ao perfil do executivo no mercado considerados mais importantes são: integridade, visão estratégica, liderança, conhecimento das operações da empresa, capacidade de decisão, negociação e coordenação de trabalhos em equipe, foco nos resultados, ética no trato das questões profissionais e sociais, motivação, pró-atividade e habilidade para o trato interpessoal.

Palavras-chaves: recursos humanos; globalização; executivos.

\begin{abstract}
The globalization process has led the Brazilian transnational companies to redefine their executives' profiles. Implementing these changes requires specific knowledge and capabilities in order to act in the current business environment. Presently, the goal of the study is to describe the profile of the executive facing the demands of a global market. We emphasized the main attributes that this executive must have as described by the visionaries of the top 500 companies ranking from Exame Magazine (1997). To do this we implemented a descriptive research in two stages: (1) an exploratory research which generated the attributes that will be evaluated and; (2) a quantitative stage to measure the degree of importance for each indicator.The executive principal attributes on the global market are: integrity, strategic view, leadership, business operations knowledge, ability to make decisions, ability to negotiate and coordinate team efforts, profit mindedness, ability to understand social and professional ethical questions, motivation, proactivity and the skills to manage interpersonal relationships.
\end{abstract}

Key words: human resource; globalization; executive. 


\section{INTRODUÇĀO}

Os anos 90 presenciaram uma mudança de paradigma no campo da administração a partir do surgimento de novas formas de corporações, que incluem parcerias estratégicas e redes organizacionais. $\mathrm{O}$ acirramento da concorrência, os rápidos avanços da tecnologia de informação e, principalmente, a globalização da economia atuaram como catalisadores no desenho de um novo ambiente de negócios (Webster, 1992).

Grieco (1997) considera que a globalização, enquanto processo de decisões articuladas, não constitui na realidade processo único e monopolítico, o que, aliás, lhe daria caráter impositivo e rígido. Há, assim, várias teorias informais que se desenvolvem em consonância aos diferentes países, com suas várias tipicidades econômicas, políticas e sociais. A globalização procura incorporar normas seletivas de investimento, levando em consideração condições macroeconômicas de mercado, recursos e estabilidade econômica.

O mercado globalizado - caracterizado pela ausência de fronteiras, empresas sem pátria e produtos sem nacionalidade - enfoca novas diretrizes para a atuação empresarial, conforme Wind (1998), tais como criação de valor, flexibilidade e aprendizagem, tecnologia da informação, mulltifuncionalidade e formação de redes a partir do estreitamento dos relacionamentos intra e interorganizacionais. Essas organizações, empresas transnacionais, devem desenvolver um entendimento mais sofisticado das diferenças culturais que marcam suas interações no ambiente global.

Com mudanças cada vez mais aceleradas, as empresas vêem-se sob uma nova pressão: recrutar, treinar e desenvolver líderes capazes de atender às demandas de um mercado globalizado. Quais são os parâmetros que irão guiar essa busca? A transnacionalização dos processos produtivos impõe uma renovação das qualificações necessárias para gerir negócios no cenário que se forma e cuja configuração difere significativamente do que o antecedeu.

Este artigo objetiva traçar o perfil exigido do executivo em face das mudanças geradas pela globalização, enfatizando-se os atributos/habilidades que assumem maior importância para a atuação eficaz nesse mercado. 


\section{Organizaçóes Globals}

O pressuposto fundamental desta pesquisa pode ser resumido nas palavras de Hesselbein, Goldsmith e Beckhard (1996), quando dizem que, a despeito da crença de que a liderança é algo inato, deve e pode ser aprendida. Assim, as habilidades e atitudes adequadas ao mercado globalizado devem ser identificadas e desenvolvidas para o alcance de uma administração eficaz e contemporânea da nova ordem econômica.

Para Handy (1995) a turbulência ambiental de uma economia globalizada exige das empresas o abandono do ideal estratégico: formalização ou flexibilidade, hierarquização ou horizontalização, entre outros. As empresas, na busca da eficiência e da eficácia de suas respostas, devem saber conjugar os antagonismos. Mais do que nunca "precisam ser globais e locais, pequenas de certo modo e também grandes, centralizadas uma parte do tempo e descentralizadas na maior parte. É esperado que os operários sejam ao mesmo tempo autônomos e integrantes de uma equipe, e que os gerentes deleguem mais e, simultaneamente, controlem mais" (Handy, 1995).

Segundo Adler (1998), a configuração deste novo panorama socio-econômico é fruto de um processo histórico de transformação do mercado. Na maioria dos casos, as companhias vivenciaram quatro estágios de operação: nacional, internacional, multinacional e, finalmente, global. O autor caracteriza o estágio nacional da organização como aquele dotado de orientação tanto de produção como de mercado local. Quando a firma se expande para mercados internacionais, o foco inicial são os mercados de países próximos, tanto geográfica como culturalmente, culminando numa distribuição multinacional. A tomada de decisão é centralizada, os lucros advêm da produção e venda em larga escala. Em cada fase, a abordagem da administração adquire novos contornos, pois a estratégia competitiva, a estrutura organizacional e a oferta de bens e serviços se alteram.

Profunda transformação cultural vem acontecendo não somente nas sociedades como um todo, mas também na cultura de cada empresa. Se quiserem sobreviver e continuar desenvolvendo-se, as organizações terão de ultrapassar as formas de trabalho da era industrial e operar com eficácia de acordo no modo pós-industrial: o da sociedade da informação. Os responsáveis pela área de recursos humanos enfrentam o desafio de exercer a liderança da transformação, interagindo com funcionários de todos os níveis, transformando-os em agentes de mudança, conscientizando-os e habilitando-os para o ambiente de trabalho emergente (Moran, Harris e Stripp, 1997). 
Moran, Harris e Stripp (1997) argumentam que as organizações globais devem agir em obediência a estes três princípios:

. Imaginar o quadro maior, ou seja, compreender os aspectos macroeconômicos, os acontecimentos sociais e demográficos e reagir mediante a adaptação de suas estratégias pessoais e de negócios.

. Preencher lacunas culturais, para que se possam comunicar com mais clareza e eficácia com pessoas que são diferentes, dessa forma aumentando a capacidade para o sucesso local e no exterior.

. Adotar um espírito global, para que se tenha uma mentalidade que permita operar eficazmente no novo cenário da economia mundial.

A visão de Moran, Harris e Stripp (1997) para o ano 2000 é que se tornará natural pensar globalmente, porque: (a) as organizações globais irão tornar-se quase indistinguíveis em termos de características nacionais, serão de propriedade de pessoas de todas as partes do mundo e seus quadros funcionais serão compostos da mesma forma; e (b) alianças estratégicas, assim como sistemas de localização, marketing e distribuição globais causarão integração e sinergia intrincada entre as economias.

A nova realidade das organizações globais causa a reestruturação de sistemas econômicos, a reorganização de papéis e procedimentos, a reorientação de setores e de organizações e a formação de alianças com aqueles que anteriormente eram vistos como concorrentes ou até mesmo inimigos.

Como esse processo de transnacionalização da economia se vem desenvolvendo no contexto brasileiro? Quais são os princípios que estão orientando as empresas nesta nova forma de pensar e administrar trazida pela onda globalizante? Que atributos, em se tratando de recursos humanos, despontam como propulsores das organizações em rede do mercado global? Essas indagações sobre os efeitos da globalização no meio empresarial brasileiro são os elementos motivadores deste artigo.

\section{As Empresas Transnacionals e os Recursos Humanos}

A globalização, compreendida como processo social genuinamente transnacional, exige reformulação do perfil do executivo: nova maneira de pensar e liderar, nova postura, apta a sustentar vantagens competitivas, num cenário de acelerada trans- 
formação. Os papéis e interações reciclam-se de acordo com as mudanças que se propagam.

Atualmente, as empresas transnacionais empregam $20 \%$ da mão-de-obra industrial global, porcentagem que chega a $40 \%$ na comunidade industrializada. Com seus próprios recursos de financiamento podem operar em todo o globo, apoiadas pelas suas próprias pesquisas científicas e tecnológicas. O papel nacional governamental limita-se mais e mais à regulamentação; muitas das transnacionais faturam, individual e anualmente, montantes que chegam a US\$ 1,5 trilhões. Metade do seu capital fixo, prédios, máquinas e centros de pesquisa, está situado no estrangeiro. Cerca de dois terços dos seus funcionários trabalham em unidades fora das nações de origem (Moran, Harris e Stripp, 1997).

Inúmeros esforços têm ocorrido no intuito de demarcação das conseqüências da globalização para a gestão empresarial e investigação das novas competências necessárias para atuação neste contexto (Nascimento Neto, 1996; Bernardi, 1998).

Moran, Harris e Stripp (1997) classificam o desenvolvimento de recursos humanos, projetado em torno da globalização, como sendo a arte de posicionar uma organização além das fronteiras nacionais, adaptando-a a quaisquer outros ambientes em mudança, onde existam mercados e recursos.

Segundo o Business International Research Report, os anos 90 testaram a capacidade das empresas transnacionais em reagir rapidamente às mudanças globais de recursos humanos, assim como em todas as outras áreas. Os métodos tradicionais de recursos humanos tiveram de ser redefinidos, ampliados e aplicados, de modo a atacar novos desafios que variam conforme o perfil da nova força de trabalho (Nascimento Neto, 1996; Bernardi, 1998).

Esse novo desafio para a área de recursos humanos é grande responsabilidade para muitos profissionais de hoje, e exigirá que eles repensem e reenquadrem seus papéis como pensadores estratégicos, gerentes sistêmicos e especialistas transculturais capazes de atender às necessidades de uma força de trabalho global para um mercado global.

\section{Método}

O universo adotado para a realização deste estudo foi composto pelos executivos das 335 maiores empresas do país localizadas nos Estados de São Paulo, Paraná, Santa Catarina e Rio Grande do Sul, segundo a classificação da Revista Exame (1997) e pelo conjunto de profissionais especialistas na área de administração. 
A distribuição do universo das empresas é a seguinte.

Tabela 1: Distribuição da População por Estado

\begin{tabular}{l|c}
\hline \multicolumn{1}{c|}{ Estado } & Número de Empresas \\
\hline São Paulo & 256 \\
Paraná & 21 \\
Santa Catarina & 19 \\
Rio Grande do Sul & 39 \\
\hline Total & 335 \\
\hline
\end{tabular}

A coleta de dados realizou-se em duas principais etapas: na primeira fase exploratória e qualitativa; no segundo momento descritivo e quantitativo. Eles serão brevemente descritos a seguir.

\section{Pesquisa Exploratória}

Os objetivos principais desta fase do estudo foram a aproximação dos pesquisadores com o tema a ser tratado (pesquisa bibliográfica) e a descrição das características do executivo necessárias para a atuação no mercado globalizado. Os itens arrolados constituíram as variáveis que integraram o questionário utilizado na pesquisa quantitativa para a mensuração do grau de importância de cada atributo.

A etapa exploratória do trabalho, desenvolvida no mês de novembro e dezembro de 1997, foi caracterizada pela realização de 19 entrevistas em profundidade com executivos e especialistas da área de administração e mais o levantamento de dados secundários em publicações recentes sobre o tema em estudo. A seleção dos elementos da amostra foi por conveniência, levando-se em conta a facilidade de acesso à alta diretoria das empresas e a disponibilidade dos executivos para o agendamento.

Foram entrevistados os executivos responsáveis pela presidência e vice-presidência das companhias ou ligados às áreas de marketing e recursos humanos. Além das entrevistas com executivos, realizaram-se também contatos com quatro peritos da área de negócios internacionais e recursos humanos.

Os atributos citados pelos entrevistados na fase qualitativa constituíram as variáveis do questionário a ser utilizado no levantamento quantitativo. 


\section{Resultados Obtidos}

Com base nos depoimentos obtidos, foram reunidos os atributos requeridos para a atuação no mercado globalizado em três grandes blocos: atitudes/valores, competências/habilidades e conhecimentos.

No primeiro, encontram-se aquelas características referentes à predisposição dos indivíduos, à sua postura e maneira de agir. Por competências/habilidades entendem-se as aptidões e capacidades propriamente ditas para o desempenho das atividades profissionais. Os conhecimentos, por sua vez, são um conjunto de informações que instrumentalizam os executivos para as suas atividades gerenciais, como o saber que o indivíduo deve possuir para que atenda às exigências do mercado.

Os atributos levantados constam em seguida.

\section{Atitudes/Valores}

. Predisposição à negociação

. Predisposição para correr riscos

. Criatividade

. Flexibilidade

. Motivação

. Intuição

.Empreendedorismo

. Ética no trato das questões profissionais e aspectos sociais

. Autoconfiança

. Mobilidade pessoal (adaptar-se rapidamente e ser favorável a mudanças)

. Capacidade de superação (principalmente no que diz respeito a situações de frustração, stress, pressão por resultados e hierarquia)

. Abertura a novas idéias

. Integridade

. Humildade 
. Vontade de autodesenvolvimento

. Atitude pró-ativa

. Atitude reativa

. Gosto pelo que faz

\section{Habilidades/Competências}

.Dimensionamento do tempo

. Coordenação de trabalhos em equipe

. Gerenciamento da inovação

. Integração das diversas áreas funcionais

. Capacidade para tratar com culturas diversas

. Antecipação de ameaças e oportunidades

. Capacidade de negociação

. Visão estratégica

. Capacidade de delegação

. Capacidade de decisão

. Habilidade interpessoal

. Capacidade de liderança

. Agilidade

. Autogerenciamento

. Resolvedor de problemas *

. Foco no resultado

. Administrador de conflito

. Desenvolvedor de pessoas*

. Capacidade de viabilizar/implementar idéias

. Capacidade de correlação de fatos com repercussões para a empresa 


\section{Conhecimentos}

. Perfil generalista

. Visão da empresa

. Conhecimentos de negócios internacionais

. Processos de alianças e joint ventures

. Outros idiomas

. Tecnologia de informação (manipulação de informação por meio de recursos computacionais)

. Titulação em cursos de pós-graduação

. Cultura de outros países/vivência internacional

.Experiência

.Especialista com visão sistêmica

\section{Pesquisa Quantitativa}

O objetivo desta etapa foi medir o grau de importância para cada um dos atributos levantados na etapa qualitativa.

Mediante os atributos identificados na fase exploratória, elaborou-se um instrumento de coleta de dados (questionário), em que cada atributo deveria receber uma nota de 0 (menos importante) a 10 (mais importante), quanto à importância deste na atuação do executivo no mercado global. O teste piloto do questionário foi realizado com 10 empresas, o que acarretou algumas modificações na forma de redigir alguns atributos.

A validação do questionário foi obtida por meio do teste de Alpha de Cronbach, visando à comprovação da fidedignidade da escala utilizada e à consistência interna do instrumento utilizado. O coeficiente do alpha de Chrombach obtido foi 0.9502 .

A amostra estudada foi composta de um total de 136 questionários respondidos, que representam um coeficiente de confiança de $95 \%$, e um erro amostral de aproximadamente $6,5 \%$.

A referida amostra pode ser considerada significativa, pois é resultante das opiniões de 136 executivos de empresas localizadas em 4 importantes Estados 
brasileiros; a grande maioria dos entrevistados são provenientes do Estado de São Paulo $(66,2 \%)$, que possui a maior concentração de grandes empresas do país (vide Tabela 2).

Tabela 2: Localização das Empresas Entrevistadas

\begin{tabular}{|c|c|c|}
\hline Estado & $N^{o}$ de Empresas & $\%$ \\
\hline São Paulo & 90 & 66.2 \\
\hline Rio Grande do Sul & 24 & 17.6 \\
\hline Santa Catarina & 11 & 8.1 \\
\hline Paraná & 11 & 8.1 \\
\hline Total & 136 & 100 \\
\hline
\end{tabular}

Algumas variáveis de interesse foram adicionadas ao estudo, visando a explorar a existência de um perfil diferenciado, que contemple fatores tais como: controle acionário, setor da empresas entrevistadas e volume de vendas em relação ao ano anterior (vide Tabelas 3, 4 e 5).

Tabela 3: Controle Acionário das Empresas Entrevistadas

\begin{tabular}{|c|c|c|}
\hline Controle & $N^{o}$ de Empresas & $\%$ \\
\hline Nacional & 89 & 65.4 \\
\hline Estrangeiro & 47 & 34.6 \\
\hline Total & 136 & 100 \\
\hline
\end{tabular}


Tabela 4: Setor das Empresas Entrevistadas

\begin{tabular}{|c|c|c|}
\hline Setor & $N^{o}$ de Empresas & $\%$ \\
\hline Setor 1 (confecçōes e têxtil) & 7 & 5.1 \\
\hline Setor 2 (comércio atacadista e varejista; distribuidora de & 24 & 16.9 \\
\hline veículos e petróleo) & & \\
\hline Setor 3 (química e petroquímica; farmacêutica; plásticos e borracha; & 26 & 199 \\
\hline limpeza e higiene ) & & \\
\hline Setor 4 (automóveis e peças; mecânica; material de transporte) & 19 & 14.0 \\
\hline Setor 5 (comunicações) & 3 & 2.2 \\
\hline Setor 6 (eletroeletrônica; computação; material de escritório) & 13 & 9.6 \\
\hline Setor 7 (alimentos; bebidas e fumo) & 18 & 13.2 \\
\hline Setor 8 (siderurgia e metalurgia) & 9 & 6.6 \\
\hline Setor 9 (material de construção) & 9 & 6.6 \\
\hline Setor 10 (papel e celulose) & 7 & 5.1 \\
\hline Setor 11 (diversos) & 1 & 0.7 \\
\hline Total & 136 & 100 \\
\hline
\end{tabular}

Tabela 5: Volume de Vendas em Relação ao Ano Anterior

\begin{tabular}{l|c|c}
\hline \multicolumn{1}{c|}{ Colume de Vendas } & No de Empresas & $\%$ \\
\hline Acréscimo & 78 & 57.4 \\
Decréscimo & 56 & 41.2 \\
Não Informado & 2 & 1.5 \\
\hline Total & 136 & 100 \\
\hline
\end{tabular}




\section{RESULTADOS}

\section{Análise Descritiva}

Pela análise descritiva, podem-se verificar as notas médias gerais para cada atributo, considerando os 136 questionários preenchidos.

Dentre os 48 atributos destacados no questionário, os que obtiveram uma nota média alta ( 9 a 10 pontos) foram: integridade, visão estratégica, capacidade de liderança, visão da empresa, capacidade de decisão, foco no resultado, ética no trato das questões profissionais e aspectos sociais, capacidade de negociação, motivação, coordenação de trabalhos em equipe, habilidade interpessoal e atitude pró-ativa.

Os atributos que obtiveram uma nota média de 8 a 9 (exclusive) foram: empreendedorismo, abertura para novas idéias, predisposição à negociação, capacidade de viabilizar/implementar idéias, desenvolvedor de pessoas, gosto pelo que faz, vontade de autodesenvolvimento, conhecimento de outros idiomas, mobilidade pessoal, antecipação de ameaças e oportunidades, criatividade, gerenciamento de inovação, perfil generalista, autoconfiança, capacidade de delegação, tecnologia de informação, integração das diversas áreas funcionais, flexibilidade, capacidade de superação, correlação de fatos com repercussões para a empresa, agilidade, autogerenciamento, habilidade em tratar com culturas diversas, experiência, administrador de conflito, predisposição para correr riscos, especialista com visão sistêmica, conhecimento de negócios internacionais e intuição.

Os atributos que obtiveram nota média de importância, mais baixa comparativamente com os outros ( 5 a 8 exclusive), foram: resolvedor de problemas, conhecimento de processos de alianças e joint ventures, conhecimento da cultura de outros países, titulação em cursos de pós-graduação, humildade e atitude reativa (vide Tabela 6). 
Tabela 6: Pontuação Geral Média dos Itens

\begin{tabular}{|c|c|c|c|c|}
\hline Item & Média & $\begin{array}{l}\text { Desvio- } \\
\text { Padnăo }\end{array}$ & $\begin{array}{l}\text { Nota } \\
\text { Maxima }\end{array}$ & $\begin{array}{l}\text { Nota } \\
\text { Minima }\end{array}$ \\
\hline Integridade & 9.51 & 0.84 & 10 & 7 \\
\hline Visão estratégica & 9.41 & 0.93 & 10 & 5 \\
\hline Capacidade de liderança & 9.40 & 0.86 & 10 & 6 \\
\hline Visão da empresa & 9.37 & 0.97 & 10 & 6 \\
\hline Capacidade de decisão & 9.29 & 0.84 & 10 & 7 \\
\hline Foco no resultado & 9.27 & 1.14 & 10 & 4 \\
\hline $\begin{array}{l}\text { Ética no trato das questóes profissionais e aspectos } \\
\text { sociais }\end{array}$ & 9.25 & 1.02 & 10 & 6 \\
\hline Capacidade de negociação & 9.24 & 0.94 & 10 & 6 \\
\hline Motivação & 9.21 & 0.98 & 10 & 5 \\
\hline Coordenação de trabalhos em equipe & 9.15 & 0.99 & 10 & 5 \\
\hline Habilidade interpessoal & 9.05 & 1.01 & 10 & 6 \\
\hline Atitude pró-ativa & 9.03 & 1.06 & 10 & 6 \\
\hline Empreendedorismo & 8.98 & 1.24 & 10 & 4 \\
\hline Abertura para novas idéias & 8.98 & 0.98 & 10 & 6 \\
\hline Predisposiçăo à negociaçăo & 8.96 & 1.23 & 10 & 4 \\
\hline Capacidade de viabilizar/implementar idéias & 8.96 & 1.05 & 10 & 5 \\
\hline Desenvol vedor de pessoas & 8.95 & 1.23 & 10 & 4 \\
\hline Gosto pelo que faz & 8.93 & 1.12 & 10 & 5 \\
\hline Vontade de autodesenvolvimento & 8.89 & 1.15 & 10 & 5 \\
\hline Outros idiomas & 8.87 & 1.35 & 10 & 3 \\
\hline $\begin{array}{l}\text { Mobilidade pessoal (adaptar-se rapidamente e ser } \\
\text { favorável a mudanças) }\end{array}$ & 8.87 & 1.28 & 10 & 4 \\
\hline Antecipação de ameaças e oportunidades & 8.85 & 1.33 & 10 & 3 \\
\hline Criatividade & 8.80 & 1,17 & 10 & 5 \\
\hline Gerenciamento de inovação & 8.79 & 1.20 & 10 & 3 \\
\hline Perfil generalista & 8.79 & 1.12 & 10 & 5 \\
\hline Autoconfiança & 8.79 & 1.22 & 10 & 5 \\
\hline Capacidade de delegação & 8.79 & 1.08 & 10 & 5 \\
\hline Tecnologia de informação & 8.69 & 1.30 & 10 & 3 \\
\hline Integraçấo das diversas áreas funcionais & 8.68 & 1.21 & 10 & 5 \\
\hline Flexibilidade & 8.68 & 1.13 & 10 & 5 \\
\hline $\begin{array}{l}\text { Capacidade de superação ( principalmente no que diz } \\
\text { respeito a situaçồ de frustração, stress, pressão por } \\
\text { resultados e hierarquia) }\end{array}$ & 8.66 & 1.18 & 10 & 5 \\
\hline $\begin{array}{l}\text { Correlação de fatos com repercussões para } \\
\text { empresa }\end{array}$ & 8.66 & 1.21 & 10 & 5 \\
\hline Agilidade & 8.63 & 1.28 & 10 & 4 \\
\hline Autogerenciamento & 8.49 & 1.32 & 10 & 4 \\
\hline Capacidade para tratar com culturas diversas & 8.49 & 1.31 & 10 & 4 \\
\hline Experiência & 8.45 & 1.29 & 10 & 5 \\
\hline Administrador de conflito & 8.43 & 1.49 & 10 & 0 \\
\hline Dimensionamento do tempo & 8.35 & 1.25 & 10 & 4 \\
\hline Predisposição para correr riscos & 8.35 & 1.43 & 10 & 3 \\
\hline Especialista com visão sistêmica & 8.11 & 1.64 & 10 & 0 \\
\hline Conhecimento de negócios internacionais & 8.10 & 1.48 & 10 & 2 \\
\hline Intuição & 8.04 & 1.31 & 10 & 4 \\
\hline Resolvedor de Problemas & 7.99 & 1.88 & 10 & 0 \\
\hline Conhecimento em processos de alianças ejoin ventures & 7.89 & 1.54 & 10 & 1 \\
\hline Conhecimento da cultura de outros países & 7.88 & 1.56 & 10 & 0 \\
\hline Titulação em cursos de pós-graduação & 7.89 & 1.77 & 10 & 0 \\
\hline Humildade & 7.84 & 1.64 & 10 & 3 \\
\hline Atitude reativa & 5.97 & 2.76 & 10 & 0 \\
\hline
\end{tabular}


Também foram calculadas as pontuações médias referentes a cada um dos 11 setores estudados, visando a uma melhor exploração dos resultados; porém, devido ao diminuto universo da amostra em alguns deles, esta análise não permitiu a realização de testes estatísticos. Com isto, podem-se destacar os 5 atributos que obtiveram as maiores pontuações médias por setor:

Setor 1 (confecções e têxtil): integridade, capacidade de decisão, ética no trato das questões profissionais e aspectos sociais, capacidade de negociação e coordenação de trabalhos em equipe.

Setor 2 (comércio atacadista e varejista; distribuidora de veículos e petróleo): integridade, visão da empresa, capacidade de liderança, capacidade de negociação e ética no trato das questões profissionais e aspectos sociais.

Setor 3 (química e petroquímica, farmacêutica, plásticos e borracha; limpeza e higiene): integridade, visão estratégica, capacidade de liderança, foco no resultado e ética no trato das questões profissionais e aspectos sociais.

Setor 4 (automóveis e peças, mecânica, material de transporte): visão da empresa, foco no resultado, integridade, capacidade de liderança e capacidade de decisão.

Setor 5 (comunicações): visão estratégica, atitude pró-ativa, empreendedorismo e desenvolvedor de pessoas.

Setor 6 (eletroeletrônica, computação, material de escritório): visão estratégica, predisposição à negociação, mobilidade pessoal, integridade, capacidade de negociação e atitude pró-ativa.

Setor 7 (alimentos, bebidas e fumo): integridade, visão estratégica, visão da empresa e capacidade de liderança.

Setor 8 (siderurgia e metalurgia): integridade, visão estratégica, visão da empresa, capacidade de liderança e foco no resultado.

Setor 9 (material de construção): motivação, capacidade de decisão, integridade e capacidade de negociação.

Setor 10 (papel e celulose): visão da empresa, capacidade de decisão, capacidade de negociação, predisposição à negociação, visão estratégica e motivação.

Setor 11 (diversos): integridade, capacidade de liderança, foco no resultado, coordenação de trabalhos em equipe, gosto pelo que faz e vontade de autodesenvolvimento. 


\section{Teste de Comparação de Médias}

O teste estatístico realizado foi o teste t para a comparação de duas amostras independentes, visando a identificar a existência de diferenças estatísticas significantes nas notas médias de importância dadas aos atributos em relação às variáveis de controle: controle acionário (nacional ou estrangeiro) e volume de vendas (acréscimo ou decréscimo no volume).

Em relação à variável controle (nacional ou estrangeiro), observa-se que os atributos considerados mais importantes pelas empresas de controle nacional do que pelas empresas de controle estrangeiro foram: humildade e gosto pelo que faz $(\mathrm{p}=0.05)$. Já os atributos/habilidades considerados mais importantes para as empresas de controle estrangeiro em relação às empresas de controle nacional foram: abertura para novas idéias, predisposição para correr riscos, coordenação de trabalhos em equipe, gerenciamento de inovação, antecipação de ameaças e oportunidades, visão estratégica, administrador de conflito, desenvolvedor de pessoas, correlação de fatos com repercussões para a empresa, flexibilidade, conhecimento de negócios internacionais, conhecimento de processos de alianças e joint ventures, outros idiomas e cultura de outros países/vivência internacional $(\mathrm{p}=0.05)$.

No que tange à variável volume de vendas em relação ao ano anterior (acréscimo ou decréscimo), pode-se observar que os atributos/habilidades que foram considerados mais importantes nas empresas que obtiveram um decréscimo nas vendas em relação às que indicaram um acréscimo foram: predisposição para correr riscos, criatividade e resolvedor de problemas $(\mathrm{p}=0.05)$.

\section{CONCLUSÓES}

A partir do estudo realizado, conclui-se que um executivo apto para atuação no mercado globalizado deve ser, em ordem de importância:

. íntegro**

. dotado de visão estratégica**

. capaz de liderar**

. conhecedor de sua empresa**

. possuidor de capacidade de decisão** 
. focalizado no resultado**

. ético no trato das questões profissionais e sociais**

. negociador**

. motivado**

. coordenador de trabalhos de equipe**

. hábil nas relações interpessoais**

. pró-ativo**

. empreendedor

. aberto a novas idéias

. dotado de postura negociadora

. capaz de viabilizar/implementar idéias

.desenvolvedor de pessoas

. uma pessoa que gosta do que faz

. motivado ao autodesenvolvimento

. conhecedor de outros idiomas

. predisposto à mobilidade pessoal

. antecipador de ameaças e oportunidades

. criativo

. gerenciador da inovação

. generalista

. autoconfiante

. capaz de delegar

. conhecedor da tecnologia de informação

. integrador das diversas áreas funcionais 
. flexível

. capaz de superação (situações de stress, frustração, pressão por resultados e hierarquia)

. capaz de correlacionar fatos com repercussões para a empresa

. ágil

. autogerenciado

. capaz de tratar com culturas diversas

. experiente

. administrador de conflitos

. dimensionador do tempo

. predisposto ao risco

. especialista com visão sistêmica

. conhecedor de negócios internacionais

. intuitivo

. resolvedor de problemas

. conhecedor de processos de alianças e joint ventures

. conhecedor da cultura de outros países

. pós-graduado

.humilde

. reativo

Durante a realização da etapa quantitativa, dos 136 executivos entrevistados nenhum acrescentou qualquer outro atributo necessário para o perfil do executivo no contexto analisado, sendo ressaltado que os 48 itens apresentados abrangeram todos os requisitos indispensáveis.

Com o objetivo de ampliar o horizonte do trabalho, algumas análises foram realizadas, considerando variáveis de controle como: setor de atuação, controle acionário, faturamento e volume de vendas em relação ao ano de 1996. 
No que tange ao fator volume de vendas, identificou-se que as empresas que apresentam decréscimo no volume de vendas atribuem maior importância à criatividade, à predisposição para correr riscos e resolução de problemas. É plausível cogitar que o resultado negativo das vendas em relação ao ano anterior tenha incentivado os executivos a valorizarem mais esses atributos.

Em relação ao setor de atividade da empresa, não foi possível obter nenhum resultado conclusivo, pois em alguns setores o número de executivos entrevistados não foi suficiente para que uma análise mais criteriosa fosse realizada. Como sugestão para futuros trabalhos, recomenda-se um estudo que aborde a importância dos atributos dos executivos em face do mercado global, a partir das peculiaridades de cada segmento de atuação.

Levando-se em consideração o controle acionário (nacional e estrangeiro), observou-se que $65,40 \%$ das maiores empresas da região sul e do Estado de São Paulo apresentam centralização do poder decisório em território brasileiro. Este fato vai de encontro ao pressuposto globalizador defendido por Moran, Harris e Stripp (1997). Tais autores enfatizam que o traço mais marcante das organizações globais é a transnacionalidade do conceito de propriedade, ou seja, a empresa realmente globalizada é aquela que não se ancora firmemente em um determinado país, da mesma forma que seu corpo funcional é constituído por indivíduos que possuem elevada mobilidade pessoal.

Os resultados obtidos com a comparação de médias sugerem que grande parte das maiores empresas dos Estados brasileiros analisadas aqui ainda não atingiram o mais avançado estágio de desenvolvimento operacional - o estágio global, conforme Adler (1998).

Realizados os testes, verificou-se que as empresas de controle nacional tendem a atribuir maior importância aos seguintes itens: humildade e gosto pelo que faz. As de controle estrangeiro, por sua vez, valorizam mais: abertura de novas idéias, predisposição para correr riscos, coordenação de trabalhos em equipe, gerenciamento de inovação, antecipação de ameaças e oportunidades, visão estratégica, administração de conflitos, desenvolvimento de pessoas, capacidade de correlacionar fatos com repercussões na empresa, flexibilidade, conhecimento de negócios internacionais, conhecimento de processos de alianças e joint-ventures, outros idiomas e cultura de outros países/vivência internacional. Disso conclui-se que os líderes das empresas com controle acionário brasileiro tendem, ao contrário das empresas com controle estrangeiro, a valorizar menos uma postura empresarial agressiva, que busca constantemente antecipar-se aos desafios e oportunidades do mercado. Dimensões tais como a busca pelo prazer no trabalho e o alcance da realização pessoal são atributos significativamente mais valorizados pelos executivos das empresas com controle nacional. 
Tais diferenças estatísticas encontradas na pesquisa devem ser entendidas tendo como pano de fundo as diferenças culturais entre os recursos humanos nos diversos países. O processo de mundialização da cultura, isto é, a extensão de um conjunto de valores, estilos, formas de pensar a uma diversidade de grupos sociais, por causa da globalização da economia, é um mecanismo lento, cujos reflexos na área de recursos humanos são menos imediatos e perceptíveis a curto prazo.

O desafio que se impõe é a reflexão contínua, pelos profissionais de administração, sobre o papel e o perfil da força de trabalho na organização que busca atender aos requisitos do mercado mundial.

Por fim, deve-se salientar que a restrição dos componentes da amostra aos Estados de São Paulo, Paraná, Santa Catarina e Rio Grande do Sul configura uma limitação desse estudo.

\section{Notas}

* As expressões resolvedor de problemas e desenvolvedor de pessoas foram mantidas conforme as designações utilizadas pelos executivos entrevistados.

** Itens que tiveram as maiores pontuações (de 9 a 10 pontos).

\section{ReFERÊNCIAS BibLIOGRÁFICAS}

ADLER, N.

Globalization and human resource management. [online] Disponível na Internet via WWW.URL : http:// www.hoshi.cic.sfv.ca/00/dlam/ business/forum/asia/adler. mar. 1998.

GRIECO, F. A.

O Brasil e a globalização econômica. São Paulo : Aduaneiras, 1997.
HAMEL, G.;

PRAHALAD, C. K.

Competindo pelo futuro. Rio de Janeiro : Campus, 1995.

HANDY, C.

A era do paradoxo. São Paulo : Makron Books, 1995.

HESSELBEIN, F.; GOLDSMITH, M.;

BECKHARD, R. (Orgs.).

O líder do futuro. São Paulo : Futura, 1996. 
MORAN, R.;

HARRIS, P.;

STRIPP, W.

Desenvolvendo organizações globais : como preparar a sua empresa para a competição mundial. São Paulo : Futura, 1997.

NASCIMENTO NETO, A.

A roda global. Veja, São Paulo, abr. 1996, p. 80-89.

REVISTA EXAME.

Edição especial. São Paulo, jul. 1997.
WEBSTER, F.

The changing role of marketing in the corporation. Journal of Marketing, v. 56, p. 01-17, Oct. 1992.

WIND, J.

Towards a new marketing paradigm. In: WINTER MARKETING EDUCATORS CONFERENCE (1998: [S.1.]). Proceedings... [S.1.] : AMA, 1998. 